\title{
PENGARUH DISIPLIN BELAJAR SISWA TERHADAP HASIL BELAJAR KELAS VI B MIN 3 MOJOKERTO
}

\author{
Sulistyowati \\ Prodi Pendidikan Guru Madrasah Ibtidaiyah Fakultas Agama Islam \\ Universitas Hasyim Asy'ari \\ E-mail: wati9712@gmail.com \\ Imam Muslich \\ Prodi Pendidikan Guru Madrasah Ibtidaiyah Fakultas Agama Islam \\ Universitas Hasyim Asy'ari
}

\begin{abstract}
Abstrak
Kedisiplinan adalah keadaan tingkah laku atau perilaku seseorang yang sesuai dengan aturan atau tata tertib sehingga tercipta ketertiban dan keteraturan. Kedisiplinan ini membantu siswa untuk menunaikan tugas dan tanggungjawab untuk mencapai tujuan. Bagaimana kedisiplinan siswa MIN 3 Mojokerto, dan hubungannya dengan prestasi belajar siswa. Dalam penelitian ini menggunakan metode angket dan dokumentasi.

Penelitian ini dilaksanakan di MIN 3 Mojokerto dengan mendapatkan hasil sebagai berikut: 1) Kedisiplinan siswa siswi VIB di MIN 3 Mojokerto, Kab. Mojokerto menunjukkan nilai sebesar 62,8\%. Apabila diinterprestasikan nilai tersebut di kategori sedang. 2) Prestasi belajar siswa siswa VIB MIN 3 Mojokerto, menunjukkan nilai sebesar 68,5\%. Apabila diinterprestasikan kategori sedang. 4) Adanya pengaruh yang signifikan antara kedisiplinan dan kemandirian belajar siswa terhadap prestasi belajar di MIN 3 Mojokerto Kab.Mojokerto Nilai koefisien jika diinterprestasikan pada nilai interpretasi koefisien korelasi dapat dikategorikan cukup kuat.
\end{abstract}

Kata kunci: Disiplin, Prestasi Belajar

\begin{abstract}
Discipline is a state of behavior or behavior of a person in accordance with the rules or order so as to create order and order. This discipline helps students to fulfill their tasks and responsibilities to achieve goals. What is the discipline of MIN 3 Mojokerto students, and how is it related to student achievement? In this study, the questionnaire and documentation method were used.

This research was conducted in MIN 3 Mojokerto by getting the following results: 1) Discipline of VIB students in MIN 3 Mojokerto, Mo.Mokokerto District showed a value of $62.8 \%$. If interpreted these values were in the medium category. MIN 3 Mojokerto, shows a value of $68.5 \%$. If interpreted the medium category. 4) There is a significant influence between discipline
\end{abstract}


and student learning independence on learning achievement in MIN 3 Mojokerto Kab. Mojokerto The coefficient value if interpreted on the interpretation coefficient correlation value can be categorized quite strong.

Keywords: Discipline, Learning Achievement

\section{PENDAHULUAN}

Pendidikan merupakan akar kehidupan yang harus dikembangkan oleh manusia terutama bangsa dan negara. Pendidikan adalah proses perbaikan yang berkelanjutan dalam kehidupan. Maka untuk pendidikan pada saat ini tidak hanya menitikberatkan pada masa lalu tetapi juga untuk mempersiapkan masa depan. Dengan ilmu pengetahuan manusia akan dapat mengambil pelajaran sesuai dengan firman Alloh dalam surat Az Zumar ayat 9 yang berbunyi:

$$
\text { ع ع عان..... }
$$

Artinya: “... Sesungguhnya (yang dapat) mengambil pelajaran(hanya) orang-orang yang memiliki akal sehat".

Harapan pendidikan di Indonesia dapat mencetak manusia yang unggul, berilmu dan berakhlak mulia sehingga mutu pendidikan perlu ditingkatkan.Guru merupakan salah satu komponen utama dalam keberhasilan belajar siswa.

Tujuan secara umum dan aturan yang berlaku di pendidikan harus dijalan. Aturan yang berlaku itu diusahakan diterapkan oleh peserta didik. Norma dan kebiasaan yang berada di lembaga ditaati oleh peserta didik dan guru sebagai teladan.

Macam pendidikan itu antara lain pendidikan di sekolah, rumah dan di masyarakat. Ketiga pendidikan saling keterkaitan. Pendidikan di masayarakat merupakan pendididikan yang melaksanakan masayarakat. Pendidikan di rumah merupakan pendidikan yang berada pada keluarga yang dibantu oleh orang tua. Pendidikan sekolah adalah pendidikan yang berada disekolah dengan pelaksana guru dan kepala sekolah serta anggota yang didalamnya. Pendidikan sekolah adalah pendidikan di sekolah yang pelaksanaannya secara sistematis, berstruktur, bertingkat dan berjenjang.

Proses kegiatan belajar mengajar akan membentuk karakter dari siswa. Karakter siswa yang akan dibentuk adalah disiplin dan kemandirian. Disiplin adalah tingkah laku yang telah memenuhi ketentuan dan aturan. Disiplin kelas adalah taktik yang dipakai oleh guru untuk menumbuhkan sikap mematuhi aturan yang berada kelas. Sudut pandang disiplin adalah taat (patuh) kepada aturan tata tertib. Islam memerintahkan untuk belajar disiplin yang terdapat dalam Hadist Bukhari yang berbunyi:

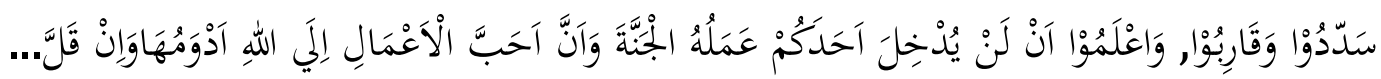
Artinya: "Tetaplah dalam kebenaran dan bersikaplah yang lurus. Ketahuilah bahwa amalan seseorang tidak dapat memasukkannya ke dalam surga dan bahwa amalan 
yang paling dicintai oleh Alloh yaitu yang dikerjakan secara terus-menerus walaupun sedikit".

Siswa yang telah melaksanakan disiplin maka akan tampak kemandirian dalam mengendalikan diri serta dapat memenuhi kebutuhan untuk dirinya. Kedisiplinan dan Kemandirian belajar dapat berjalan maka akan menjadikan siswa bertanggungjawab demi tercapainya prestasi belajar.

\section{Kedisiplinan merupakan nilai moral yang dapat dipandang oleh masyarakat.}

Disiplin adalah tindakan yang baik di masyarakat sehingga dapat diterima oleh kelompok atau masyarakat. Menurut istilah disiplin adalah sesorang yang diikuti guna belajar di bawah pengawasan seorang pemimpin. Displin adalah menetapi jalan yang lurus dan tidak menyimpang darinya (Ariany Surfiah, 2015: 2). Disiplin adalah peraturan yang ada di sekolah. Kepatuhan dan ketaatan pada hukum yang ada di bangsa ini merupakan perwujudan dari perilaku suatu bangsa. Disiplin merupakan modal utama untuk meraih kesuksesan (Erwin Widiasworo 157). Disiplin adalah suatu keadaan atau proses pengendalian keinginan, dorongan untuk mencapai tindakan yang lebih baik sehingga tidak adanya pelanggaran baik secara langsung maupun tidak langsung.

Disiplin adalah alat pendidikan untuk mengikuti dan taat peraturan yang berlaku disertai dengan adanya hukuman (Tulus Tu'us 2004: 33).

Beberapa definisi disiplin tersebut dapat dikatakan bahwa disiplin dapat terbentuk serta terwujud karena adanya faktor yakni mengikuti dan melaksanakan aturan, kesadaran dalam diri, hasil proses kegiatan belajar, hukuman demi perbaikan diri.

\section{Fungsi Disiplin}

Disiplin dapat mengiringi siswa sukses dalam belajar dan kelak ketika bekerja. Beberapa fungsi disiplin antara lain:

1) Tertatanya kehidupan Bersama

2) Membentuk karakter

3) Mengasah sikap

4) Pemaksaan

5) Tercipta lingkungan yang damai (Tulus Tu'us 2004: 33)

Sehingga disiplin bermanfaat dapat terlaksananya proses kegiatan belajar mengajar dengan lancar dan mencapai hasil yang baik. Tujuan disiplin adalah:

1. Membantu menunda kesenangan.

2. Mengembangkan bakat-bakat kita.

3. Bekerja untuk tujuan jangka panjang.

4. Membuat sesuatu untuk penghidupan kita.

Orang tua sudah memberi pengarahan kepada anak untuk bersikap dari rutinitas (Ariany Surfiah 2015: 4). Contoh disiplin yang dapat dilakukan dalam hal waktu (belajar, istirahat,mengerjakan tugas), disiplin mengerjakan sholat (waktu dan 
gerakkan), disiplin bangun tidur, disiplin belajar dan displin makan. Dan itu semua dilaksanakan atas pantauan dari orangtua karena orantua juga pendidik.

Menanamkan disiplin pada anak, perlu konsisten jika anak melaksanakan tugas dengan baik tepat waktu maka sebagai orantua diharapkan dapat memberikan penghargaan, begitu juga sebaliknya jika anak melakukan pelanggaran orang tua dapat memberikan hukuman sesuai dengan usia.

\section{Unsur-unsur Disiplin}

Tiga unsur disiplin adalah:

1) Peraturan berfungsi penanaman perilaku disiplin anak sesuai dengan lingkungan.

2) Hukuman berfungsi membuat jera terhadap tindakan yang melanggar aturan yang ada di masyarakat.

3) Hadiah untuk mmemberi motivasi untuk mengulang perilaku yang diterima secara sosial.

\section{Faktor penyebab disiplin dalam kelas}

Terbentuknya kedisiplinan adalah latihan dan pembinaan serta diri kemauan siswa. Faktor penyebab disiplin antara lainadanya kesadaran dalam diri, adanya pengikutan, alat pendidikan, hukuman, teladan.

Faktor penyebab seseorang berdisiplin baik lingkungan sekolah atau lingkungan keluarga.

\section{Indikator-sndikator Kedisiplinan}

Menaati aturan yang ada di sekolah baik yang tertulis seperti mengenai seragam sikap di sekolah harus ditaati dan di patuhi. Indikator meliputi mengatur waktu belajar, ulet, teratur belajar, focus ketika belajar di kelas, tertib diri saat belajar (Tulus Tu'us 2004: 19).

Kemandirian belajar adalah kegiatan belajar aktif atau usaha yang dimiliki. Kemandirian belajar dapat terwujudjika siswa dapat mengontrol dirinya sendiri dalam mengerjakan, mengevaluasi dan selanjutnya merencanakan pembelajaran.

Ciri-ciri kemandirian belajar :

1. Tidak menghandalkan orang lain.

2. Berani mencoba sesuatu yang baru dan berani mengambil resiko.

3. Memiliki semangat tinggi.

4. Kreatif dan produktif.

5. Bertanggung jawab.

6. Memanfaatkan segala sesuatu dengan baik (Ariany Surfiah: $2015: 6$ ).

Kemandirian belajar adalah usaha dari dalam diri untuk memilki inisiatif berkarya, rasa percaya diri tinggi, mampu mengambil keputusan, dapat dipertanggungjawabkan dan dapat bersosialisai dengan lingkungan (Negoro 2011: 17).

189 | MODELING, Volume 6, Nomor 2, September 2019 


\section{METODOLOGI}

Pendekatan yang digunakan adalah pendekatan kuatitatif. Pendekatan kuantitatif adalah pendekatan yang berdasarkan firasat positif, untuk mengkaji secara menyeluruh atau bagian tertentu. Adapun jenis penelitian yang penulis gunakan adalah deskriptif kuantitatif. Deskripsi kuantitatif ialah metode untuk menggambarkan suatu obyek, manusia, kondisi pada peristiwa masa sekarang. Variabel penelitian ini adalah kedisiplinan dan prestasi belajar siswa.

\section{Teknik Pegumpulan Data}

Cara untuk mengumpulkan data pada penelitian ini adalah metode angket dan dokumentasi.

1. Angket ialah lembaran quesioner berupa pertanyaan yang diberikan kepada responden untuk diisi atau dijawab. Angket adalah metode yang digunakan responden untuk menjawab pertanyaan atau pernyataan sehingga memperoleh data.

2. Dokumentasi adalah kegiatan agar mendapatkan barang langsung dari tempat penelitian. Dokumentasi adalah metode yang digunakan untuk mendapatkan data-data berupa dokumen atau data tertulis.

\section{Teknik Analisis Data}

Setelah memperoleh data maka dilakukan analisis terhadap variabel kedisiplinan dan prestasi belajar.Adapun analisis data yang dilakukan adalah :

1. Analisis Deskripsi adalah menggambarkan keadaan umum kedisiplinan dan prestasi belajar dengan menggunakan statistik.

2. Uji prasyarat untuk mengetahui liniear dan normalitas dari variabel

3. Analisis korelasi sederhana untuk mengetahui adanya hubungan antara variabel $\mathrm{X}$ dan variabel Y.

4. Menentukan koefisien determinasi untuk mengetahui besar kecilnya pengaruh antara variabel $\mathrm{X}$ dengan variabel $\mathrm{Y}$.

\section{PEMBAHASAN}

Data Variabel kedisiplinan ( $\left.\mathrm{x}_{1}\right)$ diperoleh dengan menggunakan angket terdiri 30 item pertanyaan dengan 35 responden. Di mana skala likert terdiri dari pilihan jawab SS, S, J, TP. Hasil penelitian yang diolah menggunakan windows excell untuk variabel kedisiplinan, skor terendah adalah 82 dan skor tertinggi adalah 109.

\section{Tabel 1.Nilai Varibel kedisiplinan Belajar}

\begin{tabular}{cccc}
\hline No & Interval Kelas & F & Persentase (\%) \\
\hline 1 & $82-85$ & 5 & 14,28 \\
2 & $86-89$ & 7 & 20
\end{tabular}

MODELING, Volume 6, Nomor 2, September 2019 | 190 


\begin{tabular}{cccc}
3 & $90-93$ & 4 & 11,43 \\
4 & $94-97$ & 4 & 11,43 \\
5 & $98-101$ & 4 & 11,43 \\
6 & $102-105$ & 5 & 14,29 \\
7 & $106-109$ & 6 & 17,14 \\
\hline & Jumlah & $\mathbf{3 5}$ & $\mathbf{1 0 0}$ \\
\hline
\end{tabular}

Tabel 2. Nilai Interprestasi Kedisiplinan Belajar

\begin{tabular}{lllll}
\hline No & \multicolumn{1}{c}{ Skor } & F & Persentase (\%) & Kategori \\
\hline 1 & $x \geq 104,5$ & 8 & 22,89 & Tinggi \\
2 & $86,9 \leq x>104,5$ & 22 & 62,86 & Sedang \\
3 & $x \leq 86,9$ & 5 & 14,29 & Kurang \\
\hline
\end{tabular}

Nlai interpretasi kedisiplinan belajar siswa kelas VIB MIN 3 Mojokerto tergolong sedang.

Data variabel kemandirian ( $\mathrm{x}_{2}$ ) menggunakan angket dengan 25 item pertanyaan yang diberikan kepada 35 responden. Skala likert terdiri dari pilihan jawab SS, S, J, TP. Peneliti mengolah data dengan bantuan menggunakan for windows excell untuk kemandirian, hasil terendah adalah sebesar 49 dan nilai tertinggi adalah sebesar 85 .

Tabel 3. Nilai Frekuensi Kemandirian Belajar

\begin{tabular}{cccc}
\hline No & Interval & f & Persentase (\%) \\
\hline 1 & $49-53$ & 3 & 8,57 \\
2 & $54-58$ & & \\
3 & $59-63$ & 4 & 11,43 \\
4 & $64-68$ & 4 & 11,43 \\
5 & $69-73$ & 8 & 22,86 \\
6 & $74-78$ & 9 & 25,71 \\
7 & $79-83$ & 5 & 14,29 \\
8 & $84-88$ & 2 & 5,71 \\
\hline \multicolumn{2}{c}{ Jumlah } & $\mathbf{3 5}$ & $\mathbf{1 0 0}$ \\
\hline
\end{tabular}

Tabel 4. Nilai Interprestasi prestasi belajar

\begin{tabular}{ccccc} 
No & Skor & F & Persentase ( \% ) & Kategori \\
\hline 1 & $x \geq 77,5$ & 9 & 25,71 & Tinggi \\
2 & $59,5 \leq x<77,5$ & 21 & 60 & Sedang
\end{tabular}

191 | MODELING, Volume 6, Nomor 2, September 2019 


\begin{tabular}{ccccc}
3 & $\mathrm{x} \leq 59,5$ & 5 & 14,29 & Kurang \\
\hline & Jumlah & $\mathbf{3 5}$ & $\mathbf{1 0 0}$ & \\
\hline
\end{tabular}

Nilai interprestasi kemandirian belajar siswa kelas VIB MIN 3 Mojokerto tergolong sedang.

Untuk mendapatkan prestasi belajar siswa menggunakan nilai rapot siswa kelas VIB MIN 3 Mojokerto semester 2, dengan cara merekap hasil nilai. Nilai terendah dicapai adalah sebesar 86 dan nilai tertinggi adalah sebesar 97.

Tabel 5. Nilai Frekuensi Varibel Prestasi Belajar

\begin{tabular}{cccc}
\hline No & Interval & $\mathbf{f}$ & $\begin{array}{c}\text { Persentase } \\
\text { (\%) }\end{array}$ \\
\hline 1 & $86-87$ & 6 & 17,14 \\
2 & $88-89$ & 5 & 14,28 \\
3 & $90-91$ & 12 & 34,3 \\
4 & $92-93$ & 7 & 20 \\
5 & $94-95$ & 4 & 11,43 \\
6 & $96-97$ & 1 & 2,85 \\
\hline \multicolumn{2}{c}{ Jumlah } & $\mathbf{3 5}$ & $\mathbf{1 0 0}$ \\
\hline
\end{tabular}

Tabel 6. Nilai Interprestasi prestasi belajar

\begin{tabular}{ccccc} 
No & Skor & F & $\begin{array}{c}\text { Persentase } \\
(\mathbf{\%})\end{array}$ & Kategori \\
\hline 1 & $\mathrm{x} \geq 93,7$ & 5 & 14 & Baik \\
2 & $\begin{array}{c}88,3 \leq \mathrm{x} \\
<93,7\end{array}$ & 24 & 68,5 & Cukup \\
3 & $\mathrm{x} \leq 88,3$ & 6 & 17,5 & Kurang \\
\hline Jumlah & $\mathbf{3 5}$ & $\mathbf{1 0 0}$ & \\
\hline
\end{tabular}

Nilai interprestasi prestasi belajar siswa kelas VIB MIN Mojokerto cukup.

\section{Uji Hipotesis}

Analisis korelasi sederhana

a. Hubungan antara kedisiplinan belajar terhadap prestasi belajar

Tabel 7. Hasil Korelasi Sederhana

\begin{tabular}{ll}
\hline Keterangan & Hasil Perhitungan \\
\hline $\mathrm{R}$ & 0,783 \\
$\mathrm{R}^{2}$ & 0,613 \\
$\mathrm{Sig}$ & 0,000 \\
\hline
\end{tabular}

MODELING, Volume 6, Nomor 2, September 2019 | 192 
Hasil uji produck moment untuk kedisiplinan terhadap prestasi belajar diperoleh rhitung sebesar 0,783 dan nilai signifikan 0,000 dengan $r_{\text {tabel }}$ sebesar 0,33 oleh karena skor $r$ hitung $>r$ tabel dan signifikan $>0,05$, maka dapat disimpulkan bahwa terdapat hubungan yang positif antara kedisiplinan belajar dengan prestasi belajar b.Hubungan antara kemandirian belajar terhadap prestasi belajar

\begin{tabular}{ll}
\multicolumn{2}{c}{ Tabel 8. Hasil analisis korelasi sederhana } \\
\hline \multicolumn{1}{c}{ Keterangan } & HasilPerhitungan \\
\hline $\mathrm{R}$ & 0,577 \\
$\mathrm{R}^{2}$ & 0,332 \\
$\mathrm{Sig}$ & 0,000 \\
\hline
\end{tabular}

Hasil uji product moment untuk kemandirian terhadap prestasi belajar diperoleh rhitung adalah 0,577 dan hasil signifikan 0,000 dengan $r_{\text {tabel }}$ adalah 0,33 . Skor rhitung $>$ rtabel dan hasil signifikan 0,05, maka dapat ditentukan bahwa adanya hubungan positif antara kemandirian belajar dengan prestasi belajar.

b. Analisis korelasi ganda

Tabel 7.Nilai analisis korelasi ganda

\begin{tabular}{ll}
\hline Keterangan & Hasil Perhitungan \\
\hline $\mathrm{R}$ & 0,793 \\
$\mathrm{R}^{2}$ & 0,629 \\
$\mathrm{Sig}$ & 0,000 \\
\hline
\end{tabular}

Hasil uji product moment untuk kedisiplinan, kemandirian belajar terhadap prestasi belajar diperoleh rhitung adalah 0,793 dan hasil signifikan 0,000 dengan rabel sebesar 0,33. Skor rhitung $>$ rtabel dan signifikan lebih kecil dari 0,05.

Tabel 8. Nilai interprestasi Koefisien Regresi

\begin{tabular}{cc}
\hline Koefisienkorelasi & Interprestasi \\
\hline $\pm 0,81$ hingga $\pm 1,00$ & Sangatkuat \\
$\pm 0,61$ hingga $\pm 0,80$ & Kuat \\
$\pm 0,41$ hingga $\pm 0,60$ & Sedang \\
$\pm 0,21$ hingga $\pm 0,40$ & Lemah \\
$\pm 0,00$ hingga $\pm 0,20$ & Tidak ada \\
& hubungan \\
\hline
\end{tabular}

Kriteria pada tabel 14 diketahui koefisien korelasi kedisiplinan, Kemandirian Belajar terhadap prestasi belajar siswa kelas VI B MIN 3 Mojokerto tergolong kuat.

Hasil analisis diperoleh adanya korelasipositif antara kedisiplinan dan Kemandirian Belajar terhadap Prestasi Belajar.Hal ini dapat ditunjukkan melalui hasil analisis korelasi product moment dengan nilai 0,793 dengan taraf signifikan 0,000 dengan $r_{\text {tabel }} 0,33$. Skor $r_{\text {hitung }}>r_{\text {tabel }}$ dan signifikan $>0,05$, artinya kedisiplinan, kemandirian belajar dengan prestasi belajar terdapat hubungan yang positif

193 | MODELING, Volume 6, Nomor 2, September 2019 


\section{Pengaruh Disiplin Belajar Siswa}

Jadi analisis data kedisiplinan dan kemandirian belajar yang mempengaruhi prestasi belajar adalah 0,629, sedangkan sisanya dipengaruhi dari luar variabel sebesar 0,371 .

\section{SIMPULAN}

Berdasarkan hasil analisa data serta pembahasan telah dilakukan dari bab sebelumnya, maka peneliti merangkum dan mengambil beberapa kesimpulan sebagai berikut :

1. Kedisiplinan siswa siswi VIB di MIN 3 Mojokerto. Kab.Mojokerto melalui teknik pengumpulan data dengan menggunakan angket yaitu menunjukkan nilai sebesar 62,8 \%. Apabila diinterprestasikan nilai tersebut berada di kategori sedang.

2. Kemandirian siswa siswi kelas VIB di MIN 3 Mojokerto Kab.Mojokerto Melalui teknik pengumpulan data dengan menggunakan angket yaitu menunjukkan nilai sebesar 60\%. Apabila diinterprestasikan nilai tersebut berada di kategori sedang.

3. Prestasi belajar siswa siswi kelas VIB di MIN 3 Mojokerto Kab. Mojokerto melalui hasil rekapitulasi raport yaitu menunjukkan nilai sebesar 68,5\%. Apabila diinterpretasikan nilai tersebut di kategori sedang.

4. Adanya hubungan positif antara kedisiplinan dan kemandirian belajar siswa terhadap prestasi belajar di MIN 3 Mojokerto Kab. Mojokerto. Melalui korelasi product moment diperoleh nilai $\mathrm{r}_{\text {hitung }} \mathrm{r}_{\text {tabel }}=0,793>0,33$ pada signifikan $>0,05$. Nilai koefisien korelasi jika dinterprestasikan pada nilai interprestasi koefisien korelasi dapat dikategorikan kuat.

\section{DAFTAR PUSTAKA}

Asrori, Muhammad, 2010, Psikologi Remaja Perkembangan Peserta Didik, Jakarta: PT. Bumi Akasara

Desmita, 2016, Psikologi Perkembangan Peserta Didik, Bandung: PT. Remaja Rosdakarya.

Hamalik, Oemar, 2013, Proses Belajar Mengajar, Jakarta: Bumi Aksara

Haris, Mujiman, 2005, Manajemen Pelatihan Pembelajaran Mandiri, Yogyakarta Hurlock, B. Elizabeth, 1978, Perkembangan Anak Jilid 2, Gelora Akasara Pratama Kesuma, Dharma, 2013, Penddikan Karakter, Bandung: Remaja Rosda Karya M. Noor, Rohinah, 2012, The Hiddin Curriculum, Yogyakarta: Insan Madani Nasir, Moh, Metode Penelitian, Bogor: Ghalia Indonesia Negoro, 2011, Kecenderungan Hidup Mandiri, Bandung: Tarsito Sudjana, Nana, 2005, Metode Statistik, Bandung: Tarsito Sudjana, Nana, 2009, Penilaian Hasil Proses Belajar Mengajar, Bandung: PT. Remaja Rosdakarya.

Sugiono, 2017, Metode Penelitian Pendidikan, Bandung: Alfabet Surfiah, Ariany, 2015, Karakter Anak Islam, Bandung: Sygma Suryabrata, Sumadi, 2006, Psikologi Pendidikan, Jakarta: Rajawali Press 
Tu'us, Tulus, 2004, Peran Disiplin pada Perilaku dan Prestasi Siswa, Jakarta: Gramedia Widiaworo, Erwin, 2017, Masalah-masalah Peserta Didik, Yogyakarta: Araska

195 | MODELING, Volume 6, Nomor 2, September 2019 